\title{
Using linear programming to make wood procurement and distribution decisions
}

\author{
By D. Hubert Burger and Mark S. Jamnick
}

\begin{abstract}
A user-friendly, computer modeling system was developed to help make decisions for a forest products firm that is organized into profit centres. Interactive data entry provides input to a linear programming model which the system automatically builds and solves. The system considers land ownership, harvest block volumes, mill requirements, stumpage prices, mill product prices, harvest methods and their costs, and shipping distances and costs. In a case study, the system produced a solution with a unit wood cost for the firm's pulpmill that was $5.1 \%$ less than the historical cost. Tradeoff analysis showed that the woodlands division has flexibility to increase its profit by up to $25 \%$ without exceeding the pulpmill's historical unit wood cost.
\end{abstract}

Key words: harvesting, linear programming, operational planning, profit centre, tradeoff, transportation, wood distribution, wood procurement
Un système convivial de simulation par ordinateur a été élaboré dans le but d'aider à prendre des décisions au sein d'une entreprise de produits forestiers gérée par centres de profits. L'acquisation interactive des données permet de produire un modèle de programmation linéaire qui est automatiquement élaboré et résolu par le système. Le système étudie le type de tenure, les volumes retirés des aires de coupe, les besoins de l'usine, les droits de coupe, les prix des produits de l'usine, les méthodes de récolte et les coûts associés, ainsi que les distances à parcourir lors de l'expédition et les coûts qui s'y rattache. Le système a produit pour cette étude de cas une solution comprenant un coût unitaire du bois pour l'usine de pâte de l'entreprise qui était $5.1 \%$ inférieur aux coûts compilés à ce jour. L'analyse des retombées a indiqué que la division des bois et forêts avait la possibilité d'accroître ses profits jusqu'à $25 \%$ sans dépasser le coût unitaire historique du bois utilisé par l'usine de pâte.

Mots clés: récolte, programmation linéaire, planification opérationnelle, centre de profits, retombée, transport, distribution du bois, approvisionnement en bois.

\section{Introduction}

Wood procurement problems require a woodlands manager to determine how to obtain the wood required by a mill such that delivered wood cost is minimized. The harvest methods and sources of wood that are available provide a number of harvesting and shipping choices. Wood distribution problems deal with minimizing the cost of distributing wood products from various sources to meet the demands of several mills. Harvesting costs 'may be included, but the focus is on the shipping choices.

A combined wood procurement and distribution problem requires a woodlands manager to minimize delivered wood cost for one mill while satisfying the requirements of several other mills. This involves making decisions about both harvesting and shipping choices for various wood products. Wood cost for the other mills may or may not be a factor in solving a combined problem, depending on mill ownership and supply arrangements.

Wood procurement and distribution decisions are crucial to the success of forest products firms. According to a 1983 estimate, harvesting and transporting wood accounted for $55 \%$ of total Canadian forest management costs (Edwards 1983). For a pulpmill, wood cost constitutes 30 to $40 \%$ of the total cost of finished product (J. MacLellan ${ }^{2}$ pers. comm., 16 May 1991).

Wood procurement and distribution decisions are particularly important to large integrated firms which are often organized into mill and woodlands divisions, each of which oper-

Faculty of Forestry and Environmental Management, University of New Brunswick, Bag \#44555, Fredericton, New Brunswick, Canada E3B 6C2.

${ }^{2}$ Regional planner, Scott Canadian Timberlands Ltd. ates as a cost or profit centre. This complicates decision making because divisions may have conflicting objectives. Furthermore, as the size of a forest products firm increases, so does the number of wood sources, products, harvest methods and destinations. This creates a large number of harvesting and shipping choices and modeling becomes necessary to help develop cost minimizing or profit maximizing strategies.

This paper reviews the approaches to making wood procurement and distribution decisions and describes a modeling system to help make these decisions for a firm that is organized into profit centres. The menu-driven system provides interactive data editing and automatically builds and solves a linear programming model. These features save time and make the model easy to use for foresters with little knowledge of linear programming. Although developed specifically for one firm, the system has a general structure and could be applied to the wood procurement and distribution problems of other firms. Results are presented from testing the system in a case study.

\section{Historical Optimization Approaches}

Linear programming (LP) is an optimization technique that uses linear equations to define a problem having a quantifiable objective and a set of resource constraints. The usefulness of LP for making wood procurement decisions was recognized in the 1960s by Silversides (1963), Winer and Donnelly (1963), and Thompson and Richards (1969). In a variation of the wood distribution problem, Pearce and Sydneysmith (1966) used LP to distribute logs among a group of mills such that economic return (revenues minus mill processing costs) was maximized for the final products (wood cost was ignored).

Three recent studies have focused on wood distribution. Churcher (1981) used LP to allocate Crown wood to mills in New Brunswick for a 10-year period based on large supply areas 
(ca. 90,000 ha) and 12 groups of mills. Walker and Preiss (1988) used mixed integer programming (a variation of LP where some of the variables are restricted to integer values) to help plan harvesting and wood deliveries for a five-year period for five mills in northeastern Ontario. Binary variables were used to harvest all or none of a given operating unit ( 250 to $5000 \mathrm{ha}$ ). Wightman and Jordan (1990) used LP to create an annual wood distribution model for nine mills in northern New Brunswick. Harvest blocks were smaller than 125 ha and could be assigned subjectively to mills prior to optimization. The model could also limit differences in average wood cost among the mills.

These three wood distribution models were limited to four or fewer roundwood products and only Walker and Preiss (1988) included harvesting costs. The three models also lacked a comprehensive, user-friendly system for handling data and for building and solving a model. Wightman and Jordan (1990) made the most progress by designing spreadsheets for data entry and developing programs to automatically build (but not solve) their model and to report on the solution. Unfortunately, their system required both a Macintosh ${ }^{\circledR}$ and an $\mathrm{IBM}^{\circledR}$-compatible microcomputer.

A combined wood procurement and distribution problem was addressed by Newnham's (1975) LOGPLAN system. In addition to harvesting and shipping costs, LOGPLAN included the inventory cost of wood held in various stores (stump, roadside, mill yard). LOGPLAN II (Newnham 1991) added regeneration choices to LOGPLAN. LOGPLAN II builds and solves its LP model, but not completely automatically. Other features may also discourage its use. First, a detailed flowchart of operations must be constructed prior to coding and entering data. Second, screen prompts provide interactive data entry but data correction and model testing require careful editing of fixed-format files.

All of the approaches reviewed above used the single objective of minimizing total cost. None of them considered that a firm organized into profit centres has conflicting objectives that must be resolved, such as minimizing wood cost for a pulpmill vs. maximizing profit for a woodlands division.

The early use of LP was hampered by a shortage of forest managers with computer skills and by limited access to mainframe computers required to solve even relatively small problems (Newnham 1991). The development of smaller, more powerful computers and foresters' greater computer literacy have improved this situation. However, any firm wishing to use computer optimization needs a system that specifically addresses its problems and is as easy to use as possible. A system's ease of use is affected by the amount of manual data processing required and the quality of its user-interface. Ease of use can determine a system's acceptance, especially when dealing with complex problems and a technique like LP, which may be viewed by forest managers as a complex black box (Jamnick 1990).

\section{Problem Description}

Scott Worldwide Inc. (Scott) is a multinational forest products firm that operates a pulpmill, Scott Maritimes Ltd. (SML), in New Glasgow, Nova Scotia. Scott Canadian Timberlands Ltd. (Timberlands) is SML's woodlands division and is organized into three regions. Timberlands as a whole, its three regions individually, and SML are all designated as profit centres. Timberland's profit is the sum of the profits of its regions.

SML has several sources of wood supply. It owns approximately 400,000 ha of fee (freehold) land, has another 80,000

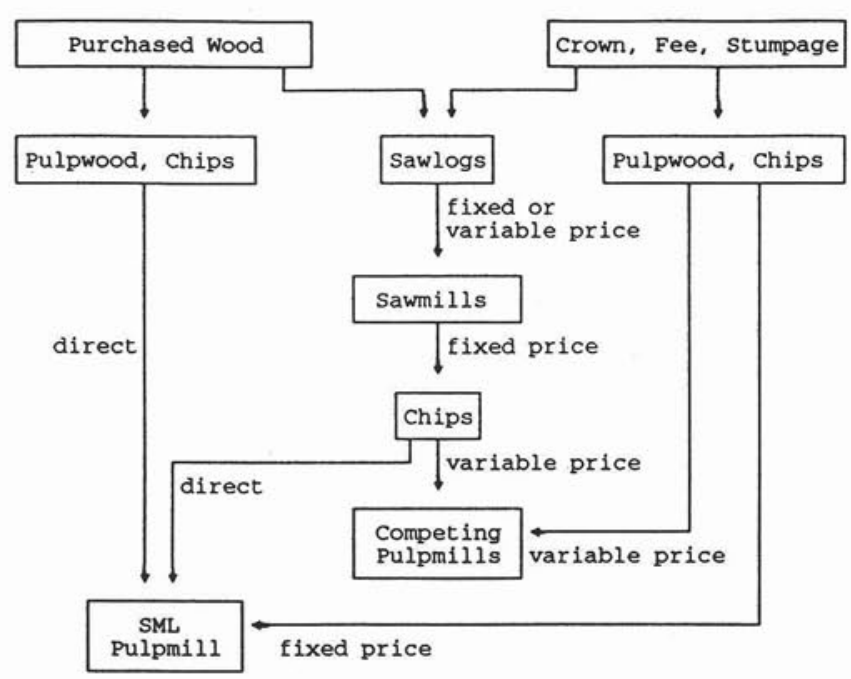

Figure 1. Wood distribution system for Scott Canadian Timberlands. Note: pulpwood may include excess sawlogs.

ha of provincial Crown land under long-term lease, and purchases stumpage from private landowners in central and eastern Nova Scotia. Additional sources include wood purchased at roadside from independent contractors, imports from outside the province, and chips from 38 sawmills in the region.

Timberlands is responsible for supplying all of the wood required by SML. It also supplies wood to several independent mills. The resulting wood distribution system is complex (Fig. 1). Timberlands supplies wood to the various mills either directly (at cost), at a fixed price (annual contract), or at a variable (market) price. The price depends on the land ownership, the mill and the product. A product is defined as a particular combination of: softwood/hardwood, sawlog/pulpwood/chips, and tree-length/random-length (not used for chips). No mills currently process hardwood sawlogs.

The amount of chips available from any sawmill is considered to be constant. If Timberlands were to reduce its supply of sawlogs to a particular sawmill, then the shortfall of sawlogs would be obtained elsewhere. Indeed, some sawmills sell chips to Timberlands without receiving any sawlogs in return.

Where Timberlands supplies wood to SML at fixed prices, the prices are determined by predicting SML's total annual wood cost, including allowances for Timberlands' overhead. This gives each region the opportunity to increase its profit if it can supply the required wood at less than the predicted cost.

Timberlands uses seven different harvest methods, each of which produces a different combination of products. Each product component of a harvest method has its own cost and utilization factor (Table 1). Some operations, such as mechanical felling and delimbing, have additional costs that vary according to harvest block conditions, such as stand yield or tree size (Table 2). Harvest blocks consist of groups of stands or parts of stands with uniform species composition. They are usually mature to overmature with a high softwood sawlog content. Block boundaries depend on landform characteristics and the location of features such as streams and wildlife corridors. Most blocks are less than $25 \mathrm{ha}$, with an average size between 15 ha and 20 ha. 


\begin{tabular}{|c|c|c|c|c|}
\hline Harvest method & Product component ${ }^{1}$ & $\begin{array}{l}\text { Utilization }^{2} \\
\text { factor }\end{array}$ & $\begin{array}{l}\operatorname{Cost}^{3} \\
\left(\$ t^{-1}\right)\end{array}$ & $\begin{array}{l}\text { Additional cost } \\
\text { required }\end{array}$ \\
\hline $\begin{array}{l}\text { Manual felling, skidding, } \\
\text { mechanical delimbing }\end{array}$ & $\begin{array}{l}\text { Softwood TL sawlogs } \\
\text { Softwood TL pulpwood } \\
\text { Hardwood RL pulpwood }\end{array}$ & $\begin{array}{l}1.00 \\
1.00 \\
0.95\end{array}$ & $\begin{array}{l}14.25 \\
21.30 \\
12.60\end{array}$ & $\begin{array}{l}\text { Mech. delimbing } \\
\text { Mech. delimbing }\end{array}$ \\
\hline $\begin{array}{l}\text { Feller buncher, forwarder } \\
\text { with flail, chipper }\end{array}$ & $\begin{array}{l}\text { Softwood chips } \\
\text { Hardwood chips }\end{array}$ & $\begin{array}{l}1.10 \\
1.10\end{array}$ & $\begin{array}{l}25.15 \\
25.15\end{array}$ & $\begin{array}{l}\text { Mech. felling } \\
\text { Mech. felling }\end{array}$ \\
\hline
\end{tabular}

${ }^{1} \mathrm{TL}=$ tree-length, $\mathrm{RL}=$ random-length.

${ }^{2}$ The utilization factor determines how much product is recovered from the forest inventory volume for that product.

${ }^{3}$ Costs are hypothetical.

\begin{tabular}{cccc}
\hline Table 2. Hypothetical costs $\left.\mathbf{(} \mathbf{t}^{\mathbf{1}}\right)$ for mechanical felling \\
\hline \multirow{2}{*}{$\begin{array}{c}\text { Stand yield } \\
\text { class }\end{array}$} & \multicolumn{3}{c}{ Tree diameter class } \\
\cline { 2 - 4 } & $\mathbf{1}$ & $\mathbf{2}$ & $\mathbf{3}$ \\
\hline A & 6.25 & 7.30 & 8.20 \\
B & 5.50 & 6.40 & 7.20 \\
C & 4.95 & 5.40 & 6.20 \\
D & 4.25 & 4.60 & 5.25 \\
\hline
\end{tabular}

Components from one or more harvest methods may be combined to form a harvest option. Using Table 1 as an example, one harvest option may consist of the softwood sawlog and pulpwood components of the manual felling and skidding method combined with the hardwood component of the chipping method. Several harvest options may be suitable for use in each harvest block.

Timberlands uses independent truckers who are paid a fixed amount $\left(\$ \mathrm{t}^{-1}\right)$ for truck loading and unloading plus a variable amount $\left(\$ \mathrm{t}^{-1} \mathrm{~km}^{-1}\right)$ according to the shipping distance.

Timberlands faces a large number of harvesting and shipping choices when making wood procurement and distribution decisions. Timberlands' prime goal is to supply wood to SML at the lowest possible cost to SML. Using manual methods to achieve this goal is difficult because of the large number of combinations of land ownerships, harvest blocks, harvest methods, products, and mills. As a profit centre, Timberlands is also concerned with maximizing its own profit. These conflicting goals must be reconciled. Assessing the tradeoffs between SML's wood cost and Timberland's profit would assist managers in resolving this conflict.

\section{Model Description}

A LP model was developed to address Timberlands' problem. The model considers land ownership (including maximum and minimum harvest levels), sawmill chip volumes, harvest block volumes, harvest methods (including production capacity and costs), shipping distances (block to mill, sawmill to pulpmill) and costs, and maximum and minimum mill requirements. Each block may have two harvest options.

The model was designed to provide flexibility in defining a problem. Mills and land ownerships are defined by the user. Stumpage prices and mill product prices may vary by product and land ownership. Timberlands' overhead allowances may also vary by land ownership. Subjective decisions may be made prior to solving a problem. A block need not be completely harvested, for example, if part of it has already been harvested. It is possible to force a block to be harvested, for example, if it is being cleaned up from a previous period. It is possible to control which block-to-mill shipping combinations are allowed, although this may limit the flexibility of the model to find the best solution. Only the products and block inventory data are predefined according to Timberlands' needs.

Wood procurement and distribution decisions may be affected by seasonal factors. Site operability may limit the season of harvest for some blocks. Some mills have seasonal operations, particularly small sawmills whose owners may pursue other seasonal occupations or who have a limited supply of logs available to them. Timberlands uses a quarterly time horizon to deal with these seasonal variations. Time is not explicitly defined in the model, so any time period may be used.

The model provides a choice of objectives and includes a set of resource and economic constraints (some are optional). An additional set of equations, called accounting rows, are used to sum various volumes, costs, and revenues. Each sum is stored in a separate variable called an accounting variable. Accounting variables simplify model construction by substituting a single variable for a sequence of variables that is repeated in several equations. Accounting variables also simplify report generation because the summed value appears in the LP solution. Accounting rows do not affect the outcome of the model and are not presented here; they are described by Burger (1991).

The model considers one type of harvesting decision and two types of shipping decisions; which are represented by the following decision variables:

$B_{\text {ih }}=$ proportion of block $i$ harvested using option $h$,

$V_{\text {phij }}=$ volume of product $p$ harvested using option $h$ in block $i$ that is shipped to mill $j$,

$C_{\mathrm{mn}}=$ volume of chips shipped from sawmill $m$ to pulpmill $n$.

Ownership is not treated as a separate attribute for the first shipping decision variable $\left(V_{\text {phij }}\right)$ because ownership can be directly determined from the block number $i$. Although the accounting rows are not presented here, the accounting variables used in the objectives and constraints are:

$M_{\text {poj }} \quad=$ volume of product $p$ received by mill $j$ from ownership $o$,

$H_{\mathrm{po}} \quad=$ total volume of product $p$ harvested from ownership $o$, $S C O S T=$ SML's total wood cost,

$T C O S T=$ Timberlands' total wood cost,

TREV = Timberlands' total revenue.

Timberlands measures volume in tonnes $(t)$, but the unit of measure is not important to the model as long as all volumes have the same units. Total costs are in $\$$ and unit costs are in $\$ \mathrm{t}^{-1}$. 


\section{Objectives}

Three main objectives may be used in the model: minimize SML's wood cost, minimize Timberlands' wood cost, or maximize Timberlands' profit. Additional objectives to maximize or minimize the harvest by land ownership may be used to assess various wood procurement policies. Objectives are expressed in terms of accounting variables. For example, the three main objectives are expressed as: maximize SCOST; minimize TCOST; and maximize TREV-TCOST.

Although the model calculates wood costs and revenues using accounting variables, Timberlands wood cost is equivalent to:

$$
\begin{aligned}
\text { TCOST }= & \sum_{\mathrm{i} \mathrm{h} \mathrm{j}} \sum_{\mathrm{pi}}\left(e_{\mathrm{phi}}+f 1+v 1 \cdot d_{\mathrm{ij}}\right)\left(V_{\mathrm{phij}}\right)+ \\
& \sum_{\mathrm{m} j} \sum_{\mathrm{j}}\left(s_{\mathrm{m}}+f 2+v 2 \cdot d_{\mathrm{mn}}\right)\left(C_{\mathrm{mn}}\right)
\end{aligned}
$$

where:

$s_{\mathrm{pi}}=$ stumpage price $\left(\$ \mathrm{t}^{-1}\right)$ of product $p$ in block $i$,

$s_{\mathrm{m}}=$ price $\left(\$ \mathrm{t}^{-1}\right)$ of chips purchased from sawmill $m$,

$e_{\text {phi }}=\operatorname{cost}\left(\$ \mathrm{t}^{-1}\right)$ of harvesting product $p$ using harvest option $h$ in block $i$,

$f 1=$ fixed cost $(\$ / \mathrm{t})$ of shipping all harvested products,

$f_{2}=$ fixed cost $(\$ / t)$ of shipping sawmill chips,

$v 1=$ variable cost $\left(\$ \mathrm{t}^{-1} \mathrm{~km}^{-1}\right)$ of shipping all harvested products,

$v 2=$ variable cost $\left(\$ \mathrm{t}^{-1} \mathrm{~km}^{-1}\right)$ of shipping sawmill chips,

$d_{\mathrm{ij}}=$ distance $(\mathrm{km})$ from block $i$ to mill $j$,

$d_{\mathrm{mn}}=$ distance $(\mathrm{km})$ from sawmill $m$ to pulpmill $n$.

SML's wood cost is calculated in a similar fashion to Timberlands' wood cost except that $j$ and $n$ are restricted to SML, and the cost coefficient for each variable is increased by the percentage of overhead allowed for each land ownership. SML's cost is also revenue for Timberlands, so Timberlands' revenue is equivalent to:

$$
\text { TREV }=\sum_{\mathrm{p} \mathrm{o}} \sum_{\mathrm{j}} r_{\mathrm{poj}} \cdot M_{\mathrm{poj}}+S M L C O S T
$$

where:

$$
r_{\mathrm{poj}}=\underset{\text { price }\left(\$ \mathrm{t}^{-1}\right) \text { of selling product } p \text { (including sawmill chips) }}{\text { from land ownership } o \text { to mill } j \text { (excluding SML) }}
$$

The objectives of minimizing SML's wood cost and maximizing Timberlands' profit address Timberlands' conflicting goals. Tradeoffs between them can be determined by minimizing SML's wood cost in conjunction with increasing levels of minimim profit for Timberlands.

The objective of minimizing Timberlands' wood cost serves three closely related purposes. First, it minimizes total wood cost for the entire wood distribution system. Second, it provides an alternative to maximizing Timberlands' profit by using an important dual property of profit maximization: if production levels are fixed (hence total revenue is fixed), then profit is maximized by minimizing total cost (Varian 1978). Third, it is an alternative to analyzing tradeoffs between SML's wood cost and Timberlands' profit. In this case, it serves to maximize overall profit for Scott (SML plus Timberlands) for a given level of production. To understand how this is accomplished, consider the elements that contribute to Scott's overall profit:

SML profit $=$ SML revenue - SML wood cost - SML other cost ${ }^{3}$
Timberlands profit $=$ SML wood cost + Timberlands other revenue - Timberlands wood cost

Scott's profit is the sum of these two profits. The two terms for SML wood cost cancel each other since SML wood cost is also revenue for Timberlands. If production levels are fixed, then total revenue (SML plus Timberlands) and SML's other cost are fixed. This leaves Timberlands' wood cost as the only variable item so, according to the dual property of profit maximization, Scott's overall profit can be maximized for a given level of production by minimizing Timberlands' wood cost.

\section{Constraints}

The resource and economic constraints of the model are expressed mathematically as:

$\begin{array}{ll}\sum_{\mathrm{h}} B_{\mathrm{ih}} \leq b_{\mathrm{i}} \quad \text { or } \quad \sum_{\mathrm{h}} B_{\mathrm{ih}}=b_{\mathrm{i}} & \text { for each } i \\ \sum_{\mathrm{j}} V_{\mathrm{phij}}-u_{\mathrm{ph}} \cdot y_{\mathrm{pi}} \cdot B_{\mathrm{ih}}=0 & \text { for each } p, h, i \\ \sum_{\mathrm{p} i \mathrm{j}} \sum_{\mathrm{phij}} \leq q_{\mathrm{k}} & \text { for each } k \\ C_{\mathrm{mn}} \geq c 1_{\mathrm{m}} & \text { for each } m \text {, where } j=S M L \\ \sum_{\mathrm{j}} C_{\mathrm{mn}} \leq c 2_{\mathrm{m}} & \text { for each } m \\ \sum_{\mathrm{o}} M_{\mathrm{poj}} \geq a 1_{\mathrm{pj}} & \text { for each } j, p \\ \sum_{\mathrm{o}} M_{\mathrm{poj}} \leq a 2_{\mathrm{pj}} & \text { for each } j, p \\ \sum_{\mathrm{p}} H_{\mathrm{po}} \geq h 1_{\mathrm{o}} & \text { for each } o \\ \sum_{\mathrm{p}} H_{\mathrm{po}} \leq h 2_{\mathrm{o}} & \text { for each } o \\ \sum_{\mathrm{po}} \sum_{0} \cdot M_{\mathrm{poj}}-S C O S T \geq 0 & \text { where } j=S M L \\ T R E V-T C O S T \geq t & \\ T R E & \end{array}$

where:

$b_{\mathrm{i}} \quad=$ maximum proportion of block $i$ that is available,

$u_{\mathrm{ph}}=$ utilization factor for product $p$ using harvest option $h$,

$y_{\mathrm{pi}}=$ total yield of product $p$ in block $i$,

$q_{\mathrm{k}}=$ capacity of harvest method $k$, where $k$ is determined from each product component of harvest option $h$,

$c 1_{\mathrm{m}}=$ minimum chip volume to be shipped from sawmill $\mathrm{m}$ to SML,

$c 2_{\mathrm{m}}=$ maximum volume of chips available from sawmill $m$, $a 1_{\mathrm{pj}}=$ minimum volume of product $p$ required by mill $j$,

$a 2_{\mathrm{pj}}^{\mathrm{pj}}=$ maximum volume of product $p$ required by mill $j$,

$h 1_{\mathrm{o}}^{\mathrm{pj}}=$ minimum volume to be harvested from ownership $o$,

$h 2_{\mathrm{o}} \mathrm{o}$ maximum volume to be harvested from ownership $o$,

$d=$ maximum unit wood cost desired by $S M L$,

$t=$ Timberlands' minimum total profit.

Constraint one sets the maximum proportion of a block to be harvested, which is usually one but may be less than one if only part of a block is available for harvest. An equality is used when a block must be harvested.

Constraint two links the total volume of a product shipped from a block with the proportion of a block that is harvested.

\footnotetext{
${ }^{3}$ SML other cost is all other manufacturing and overhead costs.
} 
Since the constraint applies to every product in a block, the linkage ensures that every product from the harvested portion of a block is shipped. This prevents cutting only a particular product from a block because it is close to a particular type of mill.

Constraint three ensures that the total volume harvested by each harvest method is less than that method's production capacity.

Constraint four sets the minimum volume of chips to be purchased from each sawmill and shipped to SML. Constraint five specifies the total volume of chips available from each sawmill.

Constraints six and seven set the minimum and maximum product requirements for each mill. Constraints eight and nine set the minimum and maximum harvest level for each land ownership.

Constraint 10 (optional) ensures that SML's unit wood cost is less than some upper limit. It may be used with any objective other than minimizing SML's wood cost. Since unit cost depends on total volume, which may vary, the constraint is expressed in terms of total costs.

Constraint 11 (optional) ensures a minimum total profit for Timberlands. It may be used with any objective other than maximizing Timberlands' profit.

\section{Modeling System}

Timberlands' staff have limited knowledge of LP, so a system was required to make solving a problem as easy as possible. Data had to be easy to handle, the mechanics of building and solving the LP model had to be hidden from the user, and useful reports had to be generated automatically from the solution. To ensure accessibility, the system had to run on Timberlands' IBM ${ }^{\circledR}$-compatible microcomputers. A system was developed consisting of a set of Turbo Pascal ${ }^{\circledR}$ programs. The system, called SOURCE, uses a menu system to control its functions. Burger (1992) provides a detailed description of how to use SOURCE.

The menu system (Fig. 2) provides interactive data entry and editing in a series of spreadsheet-style tables. This eliminates the need for the user to respond to individual prompts, edit data files directly, or worry about file formats. Data are stored in and retrieved from a set of files in $\mathrm{dBASE}^{\circledR}$ format which are automatically generated and maintained by SOURCE. Data files can be copied automatically and then edited to create various scenarios. The files can also be manipulated outside of SOURCE.

A matrix generating program builds the LP model. It identifies all of the variables (choices), calculates coefficients from the data files, and writes the objective and constraint equations of the model to a file. The model is solved using LINDO ${ }^{\circledR}$ (commercial LP software). A report writing program reads the LINDO $^{\circledR}$ solution and produces reports on blocks to harvest, harvest methods, where to ship the products from each block, volumes received by each mill, costs and revenues.

The matrix generator, LP solver, and report writer all run automatically within SOURCE, but they can be run independently to streamline the processing of a problem. Once data have been entered and an initial solution obtained, scenarios can quickly be generated and solved to test the sensitivity of the results to changes in parameters such as mill requirements, harvesting and shipping costs, stumpage prices, and product prices. Scenarios can also be processed in batches by first generating the model for each scenario and then solving and reporting on all of them in one run. This reduces the time that a manager spends at the computer and leaves more time for analysis.

\section{Case Study}

The modeling system was tested in a case study with Timberlands by creating a model of a historical scenario involving nine sawmills (sawlogs were supplied to five and chips were purchased from all nine), one pulpmill (SML), three land ownerships (Crown, freehold, stumpage), seven harvest methods, and 41 harvest blocks in Timberlands' central region. The study period was one month. The scenario included a minimum annual harvest for Crown land prorated for one month.

Additional costs were included for truck loading, equipment floating, road construction and maintenance, and administration. These costs are subject to Timberlands' overhead allowances and so affect both SML's wood cost and Timberlands' profit. SOURCE does not provide a separate way of entering these costs, but they were easily handled as additional harvesting costs, similar to additional mechanical felling and delimbing costs.

Solutions were generated for the historical scenario using each of the three main objectives. Timberlands' minimum profit was set at zero (break-even) when minimizing SML's wood cost. The upper limit for SML's unit wood cost was set at the historical level when maximizing Timberlands' profit. The solutions were compared with the historical values. Tradeoffs between SML's wood cost and Timberlands' profit were determined by minimizing SML's wood cost in conjunction with increasing levels of minimum profit for Timberlands.

\section{Results}

The LP matrix for the case study consisted of 779 variables (632 decision variables, 147 accounting variables) and 467 constraints. An IBM ${ }^{\circledR}$-compatible, $386-25 \mathrm{Mhz}$ computer generated and solved the LP matrix and produced reports for this problem in approximately seven minutes.

Model solutions relative to the historical results were summarized (Table 3). All three objectives produced solutions with lower unit wood costs for SML and Timberlands. The Timberlands objectives produced solutions with higher profit for Timberlands. Minimizing Timberlands' wood cost produced intermediate results, in terms of SML's wood cost and Timberlands' profit, compared with the other two objectives. This is because it harmonizes the extremes of the other two objectives.

The model solutions contained volumes exceeding the historical volumes, which accounts for the differences in response between total and unit costs and profits. Cost minimization should produce solutions that just satisfy minimum mill requirements. SML's minimum requirement was exceeded by $1.7 \%$ because the model was required to ship all harvested products, thereby producing excess hardwood pulpwood and softwood chips. Profit maximization also produced a solution with higher volume because Timberlands could earn more profit by shipping more wood.

Increases in Timberlands' profit were achieved mainly by shipping more wood (Table 4). There were no changes in SML's wood cost with the three lowest minimum profit levels because the model already produced more than these levels of profit. Although the minimum profit level of $\$ 150,000$ was more than Timberlands' historical profit (not shown), the resulting wood cost for SML was still less than the historical wood cost. Even the highest possible profit level produced a 
Solve a model

Quit and return to Dos

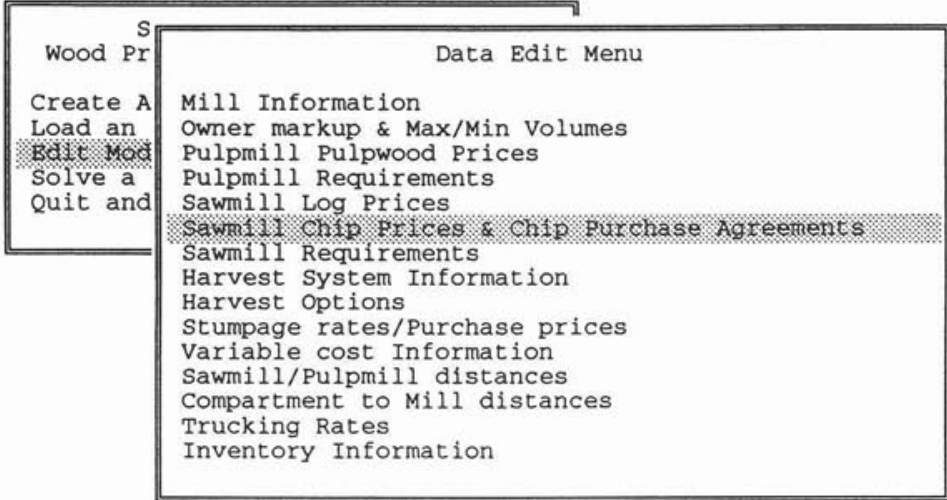

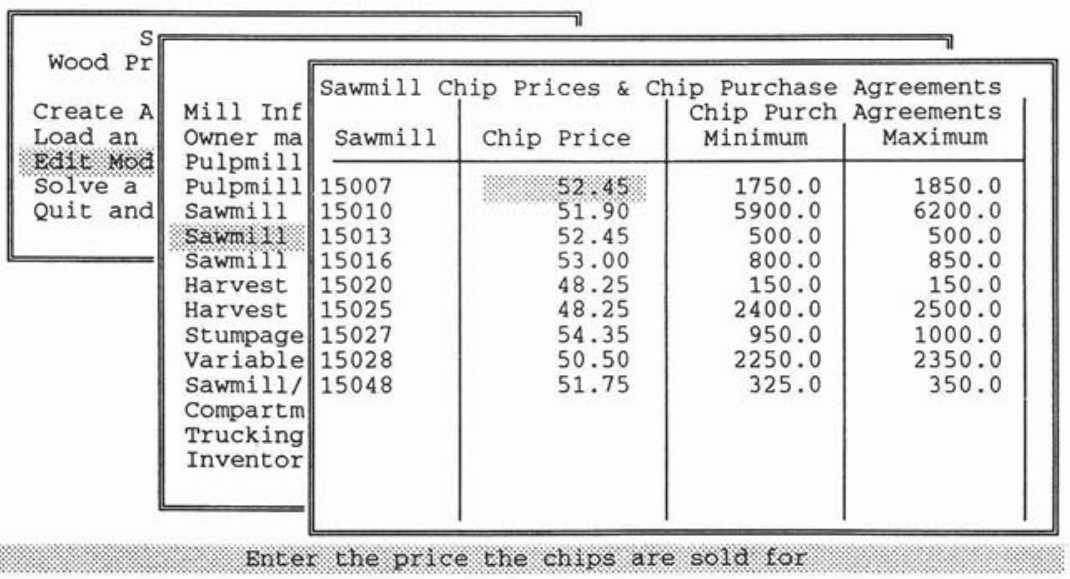

Figure 2. SOURCE's menu system. A. Main menu. B. Data-editing menu. C. Sample table for editing data (hypothetical data).

unit wood cost for SML that was less than the historical unit cost, although total cost was slightly higher than the historical value because of the higher volume. The profit levels tested were arbitrary, so the tradeoffs were not necessarily linear between profit levels.

\section{Discussion}

An operational problem for all three of Timberlands' regions would involve more blocks and mills than the one-month case study and the model would contain in the order of 5,000 variables. There is no practical limit to the size of problem that SOURCE can handle. It currently allows up to 15 land ownerships, 20 harvest methods, 50 mills and 200 blocks, and the LP software can handle up to 100,000 variables.

The case study confirmed that LP can reduce wood cost or increase profit when making wood procurement and distribution decisions. Other studies also found cost savings. Newnham (1976) found that a firm in northern Ontario could have 
Table 3. Model results compared with historical results (percent difference)

\begin{tabular}{lccc}
\hline Output & \multicolumn{3}{c}{ Objective } \\
\cline { 2 - 4 } measure & $\begin{array}{c}\text { Minimize } \\
\text { SML's } \\
\text { cost }\end{array}$ & $\begin{array}{c}\text { Minimize } \\
\text { Timberlands' } \\
\text { cost }\end{array}$ & $\begin{array}{c}\text { Maximize } \\
\text { Timberlands' } \\
\text { profii }\end{array}$ \\
\hline SML & -3.4 & -3.0 & 0.2 \\
$\quad$ Total cost & -5.1 & -4.6 & -2.5 \\
Unit cost & 1.7 & 1.7 & 2.7 \\
Volume & & & \\
Timberlands & -2.3 & -2.9 & -1.7 \\
$\quad$ Total cost & -3.6 & -4.2 & -3.8 \\
Unit cost & -1.5 & 11.8 & 25.0 \\
Total profit & -2.8 & 10.1 & 22.3 \\
$\quad$ Unit profit & 1.4 & 1.4 & 2.2 \\
Volume & & & \\
\hline
\end{tabular}

Table 4. Tradeoffs between Timberlands' profit and SML's wood cost (percent change from historical values)

\begin{tabular}{|c|c|c|c|}
\hline \multirow{2}{*}{$\begin{array}{c}\text { Timberlands' } \\
\text { profit (\$) }\end{array}$} & \multicolumn{2}{|c|}{ SML's cost } & \multirow{2}{*}{$\begin{array}{l}\text { SML's } \\
\text { volume }\end{array}$} \\
\hline & total & unit & \\
\hline 0 & -3.4 & -5.1 & 1.7 \\
\hline 50,000 & -3.4 & -5.1 & 1.7 \\
\hline 100,000 & -3.4 & -5.1 & 1.7 \\
\hline 150,000 & -2.9 & -4.7 & 1.9 \\
\hline 165,844 & 0.2 & -2.5 & 2.7 \\
\hline
\end{tabular}

reduced its wood cost by $\$ 1$ to $\$ 2$ per cord (approximately $\$ 0.40$ to $\$ 0.80 \mathrm{per}^{3}$ ). More recently, Walker and Preiss (1988) found cost savings of approximately $\$ 4$ to $\$ 5 \mathrm{per}^{3}$ and Wightman and Jordan (1990) found savings of $1 \%$ to $4 \%$ over manually generated solutions.

The $5.1 \%$ reduction in unit wood cost obtained when minimizing SML's wood cost in the case study was less than expected. This is partly because some decisions can be made intuitively (just pick the cheapest harvest methods and the closest blocks) and partly because the low mill requirements for the onemonth time frame required only 11 of the 41 blocks to be harvested. The requirement to ship every harvested product from a block meant that most blocks provided products to more than one mill. This limited flexibility in locating so few blocks to supply the six widely separated mills. A longer time frame with higher mill requirements would require more blocks to be harvested, which should allow all of a product in a particular block to be shipped to the closest mill instead of to several mills, thus providing lower unit wood costs. A larger problem with more harvesting and shipping choices would also be more difficult to solve using an intuitive approach, which cannot identify all of the tradeoffs among harvest blocks, harvest methods, products and mills. Cost savings from using SOURCE would likely be higher for larger problems.

Maximizing Timberlands profit tends to provide wood volumes near maximum mill requirements. However, a woodlands division is usually required to provide a specific volume of wood, not a volume within some range, so this objective should only be used when desired mill volumes are specified as maximum requirements. Minimizing Timberlands' wood cost avoids this problem because it is equivalent to maximizing Timberlands' profit for a given level of production. The desired production level should be specified as minimum mill requirements because cost minimization tends to minimize volume.
Minimizing Timberlands' wood cost also maximizes overall profit for Scott for a given level of production. This is easier than calculating tradeoffs and trying to select the levels of SML's wood cost and Timberlands' profit that provide the greatest overall benefit for Scott. Minimizing Timberlands' wood cost does not necessarily minimize SML's wood cost, because a higher wood cost for SML may be traded for a lower wood cost for other mills to produce the minimum overall wood cost.

SOURCE has several advantages over other recent models. First, its model is more comprehensive than the models created by Walker and Preiss (1988) and Wightman and Jordan (1990) because it considers both harvesting and shipping choices for both roundwood products and chips. SOURCE handles eight products, which is more than either of these two models. LOGPLAN II (Newnham 1991) is the only model of those reviewed that is more detailed than SOURCE.

LOGPLAN II's greater detail does not necessarily lead to better decisions than SOURCE. LOGPLAN II accounts for wood storage cost but this is less than $0.05 \%$ of total wood cost, according to an example presented by Newnham (1991), so it is unlikely to influence harvesting and shipping decisions. LOGPLAN II allows multiple time periods but SOURCE was designed to reflect the practice of planning one season or quarter at a time. With SOURCE, operations can be planned for a whole year by sequentially planning for four quarters and adjusting block availability, equipment availability and cost, and mill requirements between quarters, where appropriate.

SOURCE's second advantage is that it is more intuitive than LOGPLAN II. With SOURCE, the user specifies the product volumes available in each block and the model automatically tracks them for each harvesting and shipping choice. With LOGPLAN II, the user first specifies the total block volume, then designates special activities in the flowchart (such as slashing or trucking) to sort the harvested volume into products, and finally assigns to each sorting activity the proportion of total volume (representing a product) that may be processed by the activity. LOGPLAN II's approach also requires considerable effort by the user to properly model the choices that are available.

SOURCE's third advantage is its flexibility. Excess sawlog volumes may be used as pulpwood and a block's pulpwood volume can produce either pulpwood or chips, without any effort by the user. LOGPLAN II can also handle alternate product uses, but only by carefully designing sorting activities in the flowchart and manipulating product proportions. The other models reviewed could not account for alternative product uses.

SOURCE's fourth advantage is its ease of use. It does not require that a flowchart be created prior to entering data or when making major changes, as does LOGPLAN II. SOURCE's intuitive approach to handling product volumes is easier to use than LOGPLAN II's approach. SOURCE's menu-driven system for interactively editing data and automatically solving a problem is more user-friendly than any of the models reviewed. Furthermore, SOURCE runs on IBM ${ }^{\circledR}$-compatible microcomputers, which ensures accessibility for forest managers. SOURCE's ease of use and accessibility should encourage a manager to conduct a more detailed analysis of a problem than might otherwise occur, especially compared with manual methods.

Since the results of the case study were favourable, Timberlands intends to carry out a full-scale, operational test 
of SOURCE with a view to integrating it into their operational planning process. In the course of solving a particular problem, Timberlands will be able to use SOURCE as a simulation tool to test the impact of input parameters and constraints. In addition to general sensitivity analysis, testing can be used to evaluate:

- Volumes and prices for log supply agreements and for chip purchase agreements with various mills.

- Constraints on harvest by source (for example, a minimum harvest for the Crown lease or a ceiling on purchased wood).

- Current production capacity for a harvest method and the cost of increasing it or the benefit of reducing it.

- Opportunities to ship surplus wood to other mills.

- Planning in each region vs. planning at Timberlands main office (which could take advantage of opportunities to reduce costs or increase profits by shipping wood across regional boundaries).

\section{Conclusions}

Most studies in the past have addressed either wood procurement problems for one mill or wood distribution problems for several mills. This study was unique because it dealt with a combined wood procurement and distribution problem while addressing the conflict between the objectives of cost minimization for a pulpmill and profit maximization for the woodlands division.

The results of testing the LP modeling system that was developed for Scott Canadian Timberlands Ltd. showed that unit wood cost could be reduced for SML, that profit could be increased for Timberlands, and that Timberlands has flexibility to increase its profit above the historical level while providing wood to SML below the historical unit wood cost.

SOURCE's menu-driven system makes it easy for company staff to enter and edit data interactively and to automatically solve a problem without requiring any knowledge of LP. Once the data have been entered for a problem, various scenarios can be generated and solved to study different aspects of a problem.

SOURCE's flexibility to define a problem, the conceptually simple nature of its LP model and, perhaps most importantly, its menu system and ease of handling data should encourage forest products firms to use computerized optimization techniques to help make wood procurement and distribution decisions.

\section{Acknowledgements}

The staff of Scott Canadian Timberlands Ltd., especially Steve Rutledge, Dwight Stewart, Rick Archibald, and John MacLellan, were instrumental in explaining the details of their problem and in providing data. Ugo Feunekes, R/EMS Research Ltd., did the initial programming. R.M. Newnham and one anonymous reviewer provided helpful comments for revising this paper. This study was supported by a cooperative grant from the Natural Sciences and Engineering Research Council of Canada, Forestry Canada, and Scott Maritimes Ltd. The University of New Brunswick also provided financial assistance.

\section{References}

Burger, D.H. 1991. Analysis of wood procurement and distribution problems using linear programming. M.Sc.F. thesis, University of New Brunswick. 94 p.

Burger, D.H. 1992. User's guide to SOURCE version 1.5: a program to analyze wood procurement and distribution problems. Unpubl. man. Faculty of Forestry, University of New Brunswick. 26 p.

Churcher, R.G. 1981. An application of linear programming to Crown wood allocation in New Brunswick. M.F. report, University of New Brunswick, Fredericton, N.B. 71 p.

Edwards, A. 1983. Planning is the key to efficient reforestation. Logging and Sawmilling J., June 1983. p. 29.

Jamnick, M.S. 1990. A comparison of FORMAN and linear programming approaches to timber harvest scheduling. Can. J. For. Res. 20: 1351-1360.

Newnham, R.M. 1975. LOGPLAN — a model for planning logging operations. Can. Dep. Environ., For. Manage. Inst. Inf. Rep. FMR$\mathrm{X}-77.59$ p.

Newnham, R.M. 1976. Computer may cut costs \$1-2/cord. Pulp Pap. Mag. Can. 77(9): 73-79.

Newnham, R.M. 1991. LOGPLAN II: a model for planning logging and regeneration activities. For. Can. Petawawa Natl. For. Inst. Inf. Rep. PI-X-102. 38 p.

Pearse, P.H. and S. Sydneysmith. 1966. Method of allocating logs among several utilization processes. For. Prod. J. 16(9): 87-98.

Silversides, C.R. 1963. Linear programming applied to wood procurement. Pulp Pap. Mag. Can. 64: WR347-350.

Thompson, E.F. and D.P. Richards. 1969. Using linear programming to develop long-term, least-cost wood procurement schedules. Pulp Pap. Mag. Can. 70 (Conv. Issue): 172-175.

Varian, H.R. 1978. Microeconomic analysis. W.W. Horton \& Co., New York. 284 p.

Walker, H.D. and S.W. Preiss. 1988. Operational planning using mixed integer programming. For. Chron. 64: 485-488.

Wightman, R.A. and G.A. Jordan. 1990. Harvest distribution planning in New Brunswick. Can. For. Ind. (August) pp. 19-22.

Winer, H.I. and R.H. Donnelly. 1963. Linear programming in woodlands decisions. Pulp Pap. Mag. Can. 64: WR350-354. 